\title{
Integrated Ultrafiltration Membranes and Chemical Coagulation for Treatment of Baker's Yeast Wastewater
}

\author{
Nouri Alavijeh $\mathbf{H}^{1}$, Sadeghi $\mathbf{M}^{1^{*}}$, Rajaeieh $\mathbf{M}^{1}$, Moheb $\mathbf{A}^{1}$, Sadani $\mathbf{M}^{2}$ and Ismail $\mathbf{A F}^{3}$ \\ ${ }^{1}$ Department of Chemical Engineering, Isfahan University of Technology, Isfahan 84156-83111, Iran \\ ${ }^{2}$ Department of Environmental Health Engineering, School of Health, Shahid Beheshti University of Medical Sciences, Tehran, Iran
}

${ }^{3}$ Advanced Membrane Technology Research Centre (AMTEC), Faculty of Chemical and Energy Engineering, Universiti Teknologi Malaysia, 81310 Skudai, Johor, Malaysia

*Corresponding author: Sadeghi M, Department of Chemical Engineering, Isfahan University of Technology, Isfahan 84156-83111, Iran, Tel: +98 311 3915645; E-mail: m-sadeghi@cc.iut.ac.ir

Received date: July 13, 2017; Accepted date: July 29, 2017; Published date: August 4, 2017

Copyright: ( 2017 Alavijeh HN, et al. This is an open-access article distributed under the terms of the Creative Commons Attribution License, which permits unrestricted use, distribution, and reproduction in any medium, provided the original author and source are credited.

\begin{abstract}
An integrated system ultrafiltration membrane-coagulation has been employed for removal of chemical oxygen demand (COD) and turbidity from baker's yeast effluents. Fouling in the membrane is a common problem; chemical coagulation has been used as a pre-treatment method to mitigate fouling. Poly aluminum chloride (PACl), aluminum sulfate and lime had been used as coagulants. The results indicated that PACl exhibited higher removal efficiency than other coagulants. Two-stage coagulation and combination of coagulants were also investigated. The removal efficiency of COD and turbidity were achieved $68 \%$ and $81 \%$ by two-stage coagulation by PACl-lime, respectively. The effects of operating conditions on the ultrafiltration process for two types of hollow fiber membranes polyvinylidene fluoride (PVDF) and polypropylene (PP) on permeate flow rate, turbidity and COD removal of wastewater were further investigated. The results showed that by increasing the feed pressure, flow rate and feed temperature the permeate flow rate increased and the removal efficiency decreased. Under optimum conditions, PVDF membrane showed higher performance but compromised the flux compared to PP membrane.
\end{abstract}

\section{Keyword}

Baker's Yeast Wastewater treatment; Ultrafiltration membrane; Chemical Coagulation; COD; Turbidity removal

\section{Introduction}

Water is one of the most necessary resources for the survival of all known living species. Increasing water demand and excessive consumption of it cause to reduce freshwater resources in the world. In addition, the development of various industries and population growth will lead to a global crisis of water in the near future. The major challenge for most of the countries is providing clean water for various human activities such as drinking, agriculture, and industry [1,2]. Furthermore, severe environmental codification in order to improve the quality of the production units' effluent increases the requests for treating wastewater and reusing it in different regions of the developed and developing countries. Therefore, using new technologies in the field of wastewater treatment and reuse of wastewater have attracted great attention of scientists [3]. The use of membranes in a wastewater treatment process brings many potential advantages $[4,5]$.

- Compactness compared to biological processes

- Clean process compared to physicochemical processes, using chemicals

- The MWCO may be fitted to the characteristics of the wastewater and to the efficiency required

- High removal efficiency

- Green technology
Membrane filtrations are usually classified according to pore size to three main groups including microfiltration (MF), ultrafiltration (UF) and nanofiltration (NF). Ultrafiltration membranes have a pore size range of $0.01 \mu \mathrm{m}$ to $0.1 \mu \mathrm{m}$, and are usually characterized by their molecular weight cut-off (MWCO). UF process is able to remove viruses, emulsified oils, metal hydroxides, colloids, proteins, and other large molecular weight materials from water and other solutions[6]. The most important problem confronted in the application of membrane technology is membrane fouling. Membrane fouling contributes to membrane life decrease and power consumption increase, and gives rise to operational and economic problems for industries employing membrane separation $[7,8]$. A primary factor which intensifies fouling is natural organic matter (NOM). Membrane fouling by NOM makes the effective capacity of the process lower and decreases membrane permeate flux and also requires more frequent replacement of the membrane[9,10].

In order to prevent fouling, using pretreatment methods to decrease the feed of NOM has been a useful approach [10]. Various pretreatment methods such as chemical coagulation [11-15], electrocoagulation [16,17], adsorption[18], and ozonation [19], before the membrane technology, had been used to remove NOM and to mitigate fouling [20]. Due to the low cost and easy use of chemical coagulation, it is commonly applied and researched. Likewise, most of the NOMs, especially the hydrophobic fraction of them as well as high molecular mass (HMM) compounds, affecting membrane fouling greatly, can be removed by chemical coagulation [21].Chemical coagulation is a process to destabilize the colloids by forcing small particles to aggregate and to form larger structures (flocs)[22]. The NOM removal by chemical coagulation occurs through combination of four aggregation mechanisms, namely charge neutralization, 
entrapment, adsorption, and complexion with inorganic coagulants such as aluminum and iron salts, or perhydrolized aluminum coagulants, e.g. polyaluminum chloride $(\mathrm{PACl})$ and poly(aluminum sulphate) (PAS). In recent years, $\mathrm{PACl}$ has so far been applied in water and wastewater treatment due to high efficiency in low dosage ranges, low sensitivity to solution temperature, and its low impact on $\mathrm{pH}$ of treated water. PACl contains significant amounts of known as Al13 or Alb. This compound has been observed the most efficient Al-species for contaminant removal due to its larger size and higher positive surface charges $[23,24]$.

One of the most common problems about $\mathrm{PACl}$ is Light and floating flocks that cause poor sedimentation and Low Quality effluent [25]. In this situation, the use of ultra-filtration membranes after coagulationssedimentation processes has significant effect in effluent quality. Actually, chemical coagulation significantly promoted permeation rates, although it has less impact on the wastewater quality. On the other hand, membrane filtration has high particle removal regardless of coagulation pretreatment.

Baker's yeast industries generally use molasses as the raw materials include operations and processes such as molasses preparation, fermentation, and separation and drying of yeast and produce a large quantity of wastewater. The main problems in the treatment of baker's yeast wastewater are color, odor and high concentration of COD in the effluent. In recent years, due to the high concentration of pollutants in the effluent of this industry, a wide variety of stand-alone processes including biological such as aerobic and anaerobic treatments, physicochemical including chemical coagulation, adsorption and membrane separation processes and electrochemical procedures like electrocoagulation technology [26-35] have been reported for the treatment of baker's yeast wastewater. The results of the relevant studies show that the pigments (melanoidin) in molasses wastewater are refractory to bio-degradation. For example, Pirsaheb et al investigated the removal of color and COD from baker's yeast wastewater using anaerobic baffled reactor and the results of removal efficiency of color and COD were about $43 \%$ and $95 \%$, respectively. On the other hand, using electrochemical methods are commonly associated with less effective to remove COD, high equipment, and operational costs. Using electrocoagulation was studied by Kobya et al for baker's yeast wastewater. Under the optimal conditions, COD and turbidity removal efficiency about to $71 \%$ and $90 \%$ be achieved, respectively. Moreover, coagulation removal of COD and color from yeast wastewater using aluminum sulfate was investigated by Zhou et al. Experimental results in this study indicated that the removal efficiency of COD and color were $67 \%$ and $89 \%$, respectively. Thereupon, the contaminant removal by stand-alone processes is not sufficient and in order to achieve a high degree of purification, using combination method is necessary [36].In our previous work, we used hollow fiber membrane and filamentous fungus in MBR of baker's yeast wastewater treatment. COD and BOD5 of the wastewater were reduced to 488 and $70 \mathrm{mg} / \mathrm{L}$, respectively, over a period of 45 days, while the turbidity of the wastewater reduced from 134-282 NTU to less than 2.5 NTU in the permeate stream $[37,38]$.

The purpose of this study was to optimize the coagulation process as a pretreatment for UF membrane and to study the effects of the parameters that influence over membrane permeate flux and its quality. Moreover, the combination of coagulation and UF processes is compared with the coagulation alone and UF-alone processes in optimal conditions. This study attempts to elaborate the important of an integrated system of membrane process with conventional chemical coagulation in treating the wastewater from baker yeast production.

\section{Materials and Methods}

\section{Wastewater characteristics and coagulation procedure}

The baker's yeast wastewater used in this study was obtained from the Dezmayeh Baker's Yeast factory in Dezfoul, Iran. The raw wastewater is characterized by a $\mathrm{pH}$ of 7.5-7.9; turbidity of $1370 \mathrm{NTU}$ and the concentration of COD of $13000 \mathrm{mg} / \mathrm{L}$. Coagulation/ flocculation tests were performed using a conventional jar tester (Model PB-900, Phipps \& Bird). For each trial, 1 L samples were poured into $1 \mathrm{~L}$ beakers. Coagulant was added and then jar tests began with rapid mixing at $100 \mathrm{rpm}$ for $5 \mathrm{~min}$, followed by slow agitation of $40 \mathrm{rpm}$ for $15 \mathrm{~min}$. Subsequently, the formed flocs were allowed to settle. After sedimentation, approximately $40 \mathrm{~mL}$ samples were withdrawn with a pipette from near $2 \mathrm{~cm}$ below the surface for analysis. The $\mathrm{pH}$ was adjusted to desirable value using concentrated sulfuric acid or $1 \mathrm{M}$ solution of sodium hydroxide. All of the experiments were carried out at ambient temperature (25-28). Poly aluminum chloride (PACl), aluminum sulfate $\left(\mathrm{Al}_{2}\left(\mathrm{SO}_{4}\right)_{3}\right)$ and lime $\left(\mathrm{Ca}(\mathrm{OH})_{2}\right)$ were used as coagulant to remove color and chemical oxygen demand (COD) from molasses effluent. In addition, the main operating conditions such as $\mathrm{pH}$ and coagulant dosage were investigated for each coagulant. Then the coagulated/flocculated wastewater was transferred for ultrafiltration. A schematic diagram of experimental setup is shown in Figure 1.

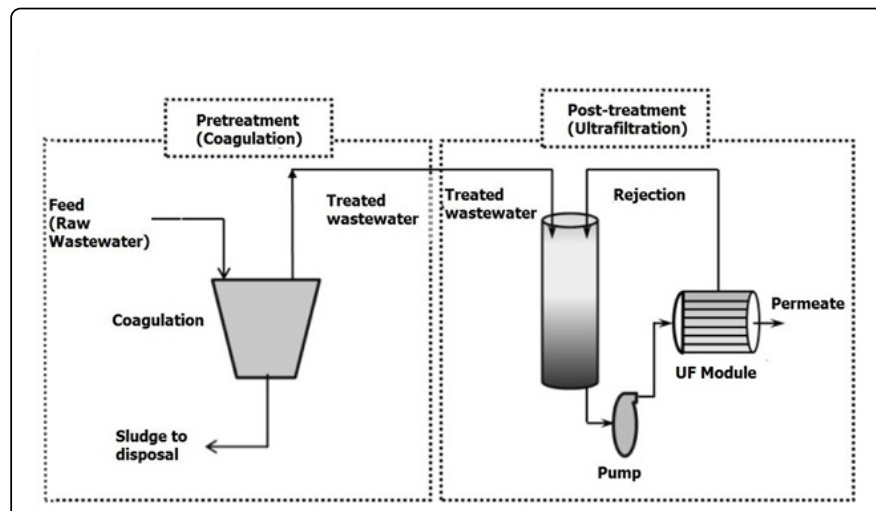

Figure 1: Schematic diagram of the experimental setup of CC/UF combination.

\section{Ultrafiltration procedure}

Ultrafiltration experiments (cross flow) were carried out on the commercial hollow fibers membranes made of polyvinylidene fluoride (PVDF) and polypropylene (PP) (Parsian Pooya Polymer Co., Iran) with a lab-scale pilot. Due to outstanding properties of PVDF membranes such as high thermal stability, good chemical resistance, and resistance to most of the corrosive chemicals and organic compounds, PVDF membranes have been handled by many researchers and industries [39]. On the other hand, the PP ultrafiltration membrane was applied due to larger pore size than the PVDF membrane which provides higher amount of flux in spite of lower quality. Before the feed solution was introduced into the membrane unit, deionized water was filtered at different set flow rates until a stable pressure was reached for each flow rate. The characteristics of the membranes are tabulated in Table 1. 


\begin{tabular}{|c|c|c|c|c|}
\hline $\begin{array}{c}\text { Membrane } \\
\text { material }\end{array}$ & $\begin{array}{c}\text { Pore size } \\
(\mathbf{n m})\end{array}$ & $\begin{array}{c}\text { Effective } \\
\text { surface area } \\
\left(\mathbf{m}^{2}\right)\end{array}$ & $\begin{array}{c}\text { Max. } \\
\text { pressure } \\
\mathbf{( b a r )}\end{array}$ & $\begin{array}{c}\text { Outer/Inner } \\
\text { Diameter }(\mathbf{m m})\end{array}$ \\
\hline PVDF & 40 & 0.6 & 4 & $1.3 / 0.7$ \\
\hline PP & $100-200$ & 1.5 & 4 & $0.5-0.55 / 0.35-0.4$ \\
\hline
\end{tabular}

Table 1: Ultrafiltration membranes characteristics.

\section{Results and Discussion}

In this study, an integrated method in two stages was utilized for the treatment of wastewater and the aim of this approach is to decline the overall contamination of the wastewater in a variety of conditions. All of the experiments were carried out in duplicate.

\section{Coagulation}

With the coagulation as a pretreatment, the coagulant concentration and initial solution $\mathrm{pH}$ were the most effective parameters which should be considered.

\section{Effect of coagulants and their concentration}

Jar tests were performed on samples with different concentrations of three types of coagulants to investigate the effects of the coagulants concentration. Actually, the effectiveness of coagulation to remove NOM substantially depends on the properties of NOM and the coagulant dose. Baker's yeast wastewater consists of Melanoidins, one of the HMM polymers. The predominant mechanism for wastewater treatment by HMM NOM is chiefly charge neutralization [40]. Figure 2 illustrates the effects of $\mathrm{PACl}$, alum, and lime dosages on the COD and turbidity removal efficiency at constant initial $\mathrm{pH}$ of wastewater. The results indicate that the COD removal efficiency reached to its maximum by enhancement of the coagulant dosage.For $\mathrm{PACl}$, alum and lime, the highest COD removal efficiency were 51, 45 and $40 \%$ respectively. Correspondingly, the optimum concentration of coagulants would be 500,800 and $1800 \mathrm{mg} / \mathrm{L}$. Melanoidins is high molecular weight nitrogenous polymers and have negative charges due to the dissociation of functional groups. Liang et al study shows that ferric chloride has higher melanoidin removal compared to alum. The reason was higher affinity of ferric ion to the reaction sites of Melanoidins. The results also showed that $\mathrm{PACl}$ was more effective than alum and lime to remove COD and turbidity. Uses of PACl in the treatment of dyes wastewater formed aluminium hydroxo-complexes during hydrolysis reaction, resulting in a high volume of precipitates consist of insoluble aluminum poly-hydroxides [41]. High efficiency removal by $\mathrm{PACl}$ can be the reason of absorbed onto the positively charged surface of the hydroxo-complexes due to Melanoidins functional groups through electrostatic attraction.

According to the findings reported by Liang et al, removal efficiency first increases with raising coagulant dosage, reaching the maximal value, and then declines with further coagulant addition[30]. The Addition of the coagulant dose greater than $500 \mathrm{mg} / \mathrm{L}$ of $\mathrm{PACl}$ resulted in positive charge induction to the complexes intensified repulsive forces between them. This phenomenon could bring destruction to the formed flocs; thus, both of the removal efficiency for COD and turbidity decreased severely. Moreover, the amount of COD and turbidity did not considerably decrease at very high doses of alum (>1000 mg/L) Soh et al. [42] reported that for alum, larger MM components of effluent are removed efficiently, nonetheless lower MM components are recalcitrant against removal by coagulation. The extracted results from Figure 2 suggest that initial enhancement of alum and lime coagulants would lead to significant increase in removal efficiency; while after elimination of larger MM particles the effect of additional coagulant dose on the removal of residual lower MM particles is negligible.

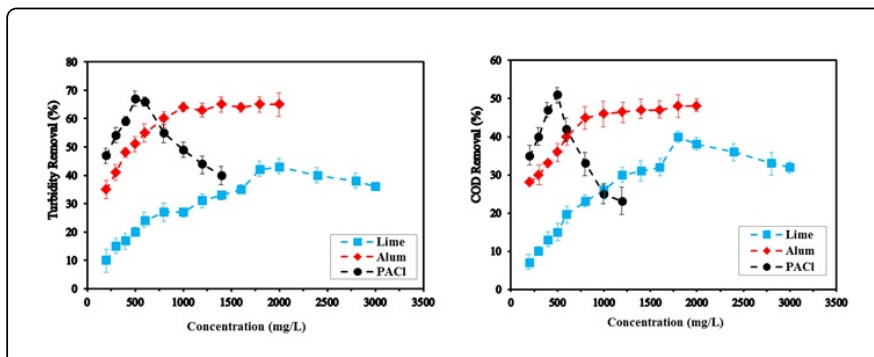

Figure 2: Effect of coagulants' concentration on (a) COD removal; (b) turbidity removal.

\section{Effect of initial pH}

The main aim of this experiment was to investigate the influence of initial $\mathrm{pH}$ of wastewater on coagulation efficiency at the predetermined optimum coagulants concentrations. In all coagulation mechanisms based on behavior and interaction of colloids, the formation of metal hydroxides depends on the surface charge. In addition, the surface charge of the colloids is a function of $\mathrm{pH}$ of the solution. The results indicate that in the case of baker's yeast wastewater, the highest removal rate is in the alkaline $\mathrm{pH}$ range from 8 to 10 (Figure 3). On the contrary, the removal efficiency decreased in acidic $\mathrm{pH}$. Similar findings have been previously reported by Liang et al. [30], Zhou et al. [32] and Liang et al. [31]. At the acidic range of pH, excessive absorption of $\mathrm{H}+$ and highly charged particles lead to breakup of the electrical interaction of colloids. As a result of the small flocs, the rate of destabilization of colloids is low [43,44].In this case, it seems that the flocs have been formed in the higher range of $\mathrm{pH}$ by trapping wastewater particles in the polymeric chain of coagulant. This mechanism is called sweep coagulation; the particles in the baker's yeast wastewater may form the core of the flocs whichcan aggregate to form sediments. These sediments will be finally deposited [45].

The obtained results suggest that the hydrolysis of $\mathrm{PACl}$ strongly depends on $\mathrm{pH}$ (Figure 3). In acidic condition, PACl is hydrolyzed as monomer and in neutral condition, it converts to multi-core and $\mathrm{PACl}$ comes into compounds such as or under alkaline condition [46]. Each of these species has different coagulation mechanisms in the effluent, i.e. the ions form flocs by charge neutralization mechanism and the aluminum hydroxides use sweep coagulation and bridge-aggregation mechanisms. Sweep coagulation achieves higher coagulation efficiency rather than other mechanisms [45,47].

Accordingly, the highest COD and turbidity removal efficiency achieved in the alkaline range of $\mathrm{pH}$ about 8-10 using PACl. 

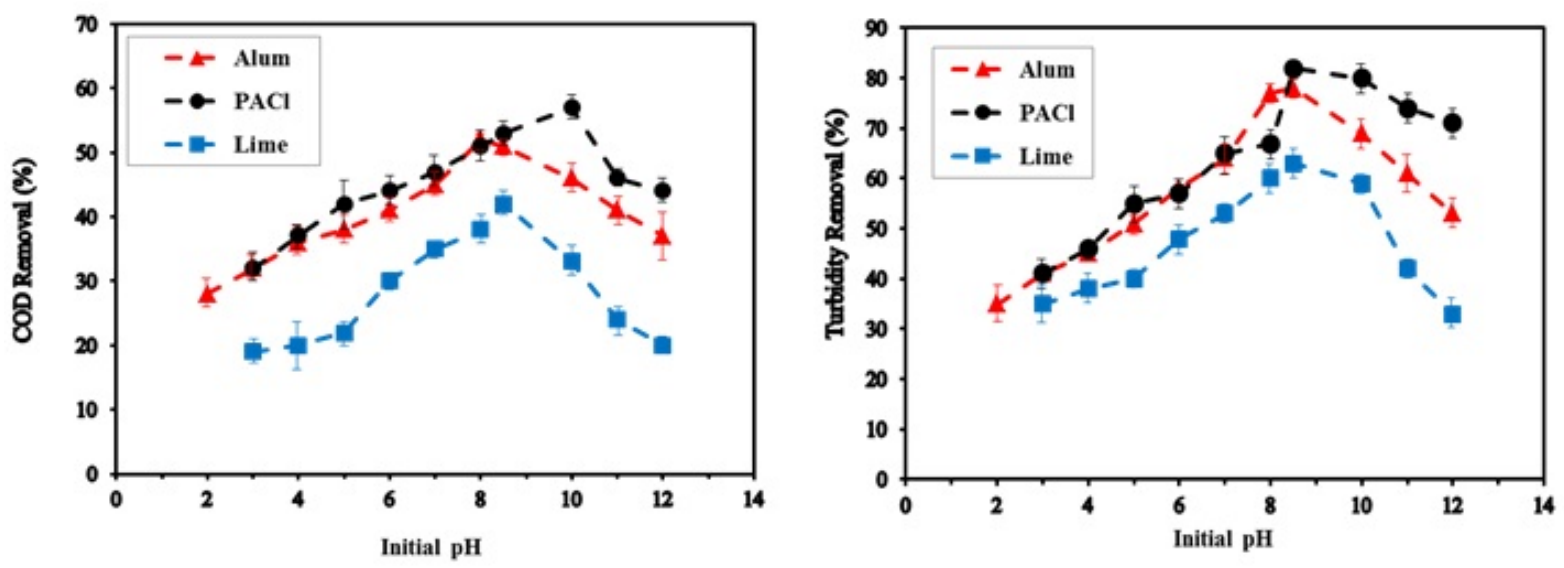

Figure 3: Effect of Initial pH on (a) COD removal, (b) turbidity removal.

\section{Two-stage coagulation and combination of coagulants}

In order to determine the highest removal rate in the pre-treatment, the effects of two-stage coagulation and the combination of two coagulants were investigated. In this process, at least one of the coagulants is selected among inexpensive ones to consider the economical consideration. In this study, the $\mathrm{PACl}$ as an effective coagulant and lime as an inexpensive coagulant were combined. The experiments included 3 methods that are suggested, as follows:

- Coagulation of raw wastewater by $\mathrm{PACl}$ (in the optimum condition) and then coagulation of the treated wastewater in the previous stage by various lime dosages (Figure 4).

- Coagulation of raw wastewater by lime (in optimum condition) and then coagulation of the treated wastewater in the previous stage by various PACl dosages (Figure 5).

- Coagulation of raw wastewater by two coagulants $\mathrm{PACl}$ and lime in optimum dosage of each one simultaneously.

Figure 4 and 5 show two-stage coagulation methods are effective in terms of removal efficiency. It is likely that the broken flocks that have not sufficient density to deposit can be reformed during the second stage. Then, they can further connect and aggregate to higher effective density and size[45]. The maximum COD removal efficiency of methods 1,2 and 3 were 68,63 and 53\% respectively. Therefore, method 1 was membrane pretreatment method in this study. The advantages of using two-stage coagulation by lime and $\mathrm{PACl}$ were that in addition to promotion of removal efficiency. On the other hand as alkaline property of lime, we saw that it increased $\mathrm{pH}$ of the wastewater in optimum $\mathrm{pH}$ range of $\mathrm{PACl}(8-10)$ and, therefore, we didn't need to add $\mathrm{NaOH}$ to increase $\mathrm{pH}$ value.

\section{Ultrafiltration}

Effect of transmembrane pressure (TMP): Transmembrane pressure affects the behaviour of membrane. By increasing pressure, the driving force which is needed for fluid to pass through the membrane increases. This phenomenon leads to an increase in flux (Figure 6). Base on Darcy's law, increasing pressure results in rising permeate flux although leads to compression of the sediments, and accelerates fouling on the surface of the membrane pores $[49,50]$. All of the experiments were conducted at the constant operating temperature of $14^{\circ} \mathrm{C}$ and velocity of $2 \mathrm{~m} / \mathrm{s}$ to evaluate the effect of the transmembrane pressure on the permeation flow independently.

Moreover, by comparison of the results of PP and PVDF efficiency, it can be found that the removal efficiency of PVDF membrane is greater than PP membrane, and that is why the differences in the structure of these membranes.

Effect of feed temperature: The effects of feed temperature on permeate flux for both of the PVDF and the PP membranes are depicted in Figure 8. The results reveal that the permeate flux increases by enhancing the temperature of the feed from 15 to $60^{\circ} \mathrm{C}$. It can be theoretically concluded as temperature increases, the diffusion coefficient increases while viscosity decreases leading to a reduction of the Schmidt number .In addition, feed temperature increment affects the size and density of membrane network pores resulting in an increase in permeate flux [51-54] also reported a $60 \%$ increase in permeate flux by enhancing the feed temperature from 20 to $40^{\circ} \mathrm{C}$. Furthermore, the effect of feed temperature on COD and turbidity removal efficiency is shown in Figure 9. The removal efficiency of the UF membranes decreases by rising temperature. In fact, increasing temperature causes a decline in the size of colloids and deformation of particle aggregates to sub-micron size range which can cross through the membrane pores easily [55].Therefore, increasing temperature, increases permeate flux of the membrane and cross contamination particles of the feed and the membrane removal efficiency decrease. 


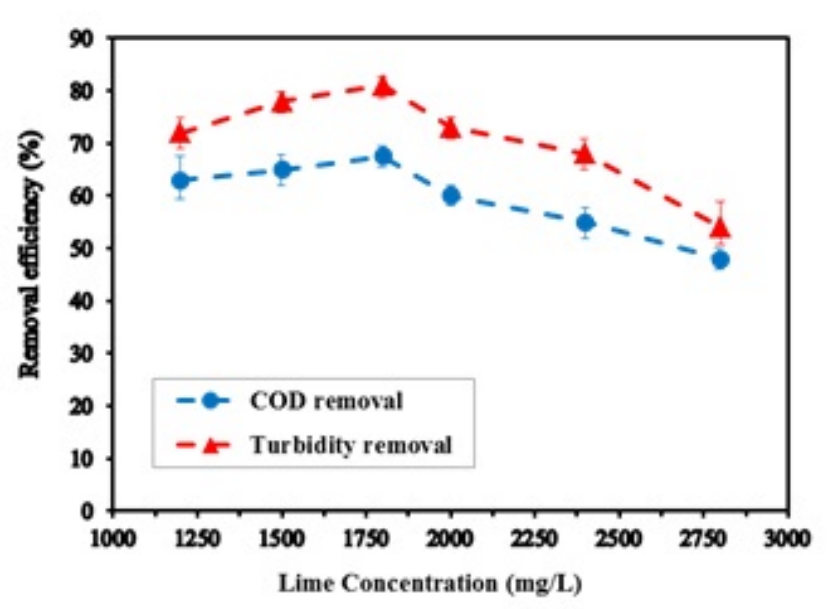

Figure 4: Effect of lime concentration on COD removal efficiency of treated wastewater by $\mathrm{PACl}$ in concentration of $500 \mathrm{mg} / \mathrm{l}$.

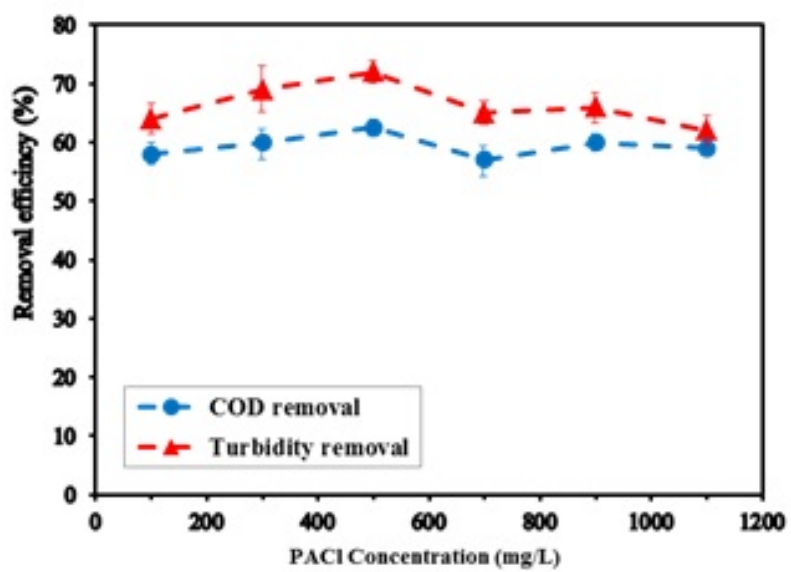

Figure 5: Effect of PACl concentration on COD removal efficiency of treated wastewater by lime in concentration of $1800 \mathrm{mg} / \mathrm{l}$.

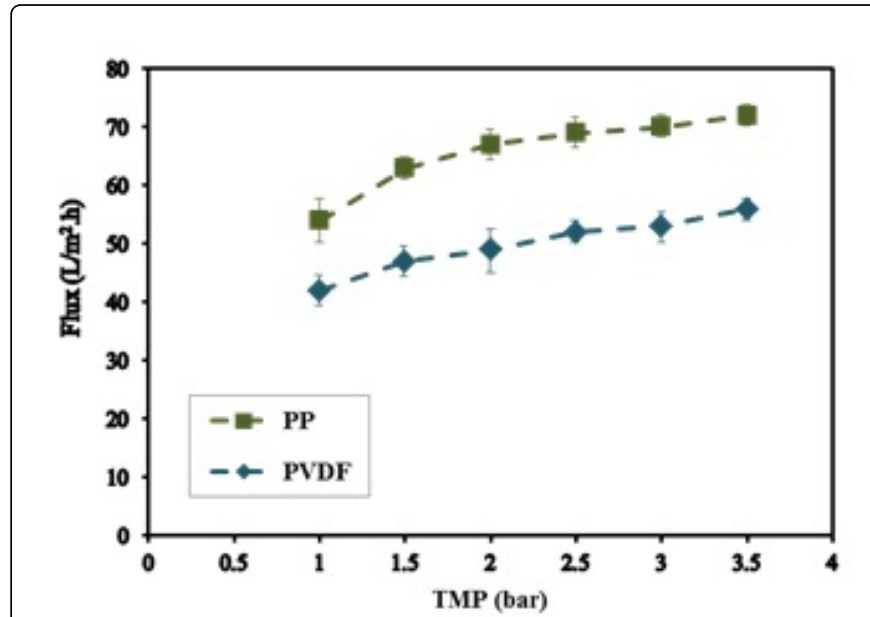

Figure 6: Effect of transmembrane pressure on permeate flux.

The results, as shown in Figure 7, show that the removal efficiency of COD and turbidity decreased as pressure increased. Indeed, permeate flow rate increases by enhancing transmembrane pressure. Therefore, the possibility of cross contamination particles increases and reduces the membrane removal efficiency [51].

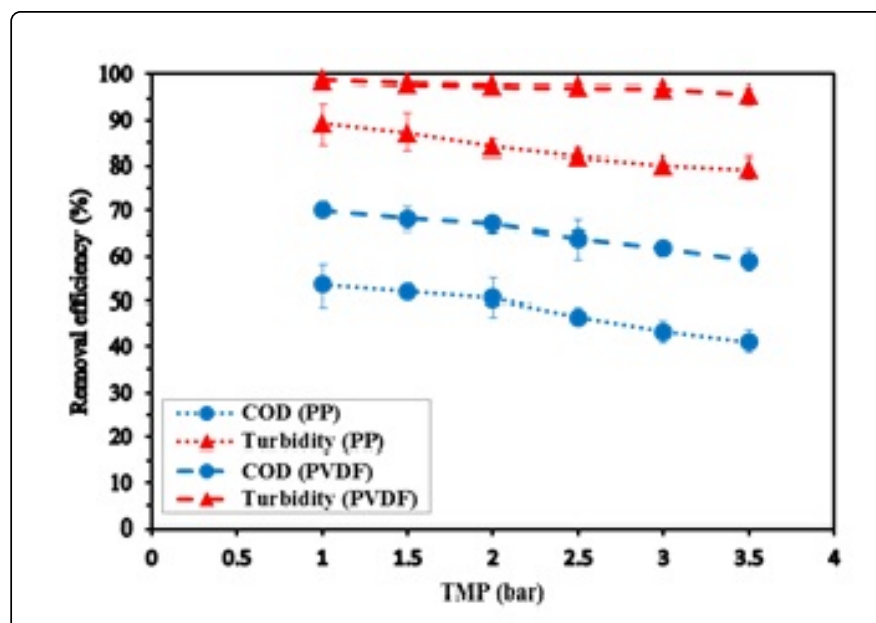

Figure 7: Effects of TMP on COD and Turbidity removal.

Effect of cross flow velocity: The effects of cross flow velocity on permeate flux and removal efficiency of the membranes was studied by some experiments within a velocity range of $1-3 \mathrm{~m} / \mathrm{s}$. The reported results in Figure 10 show that increasing velocity causes an increase in turbulence and mass transfer coefficient. Therefore, the effect of polarization is weakened and the permeate flux increases significantly [56]. 


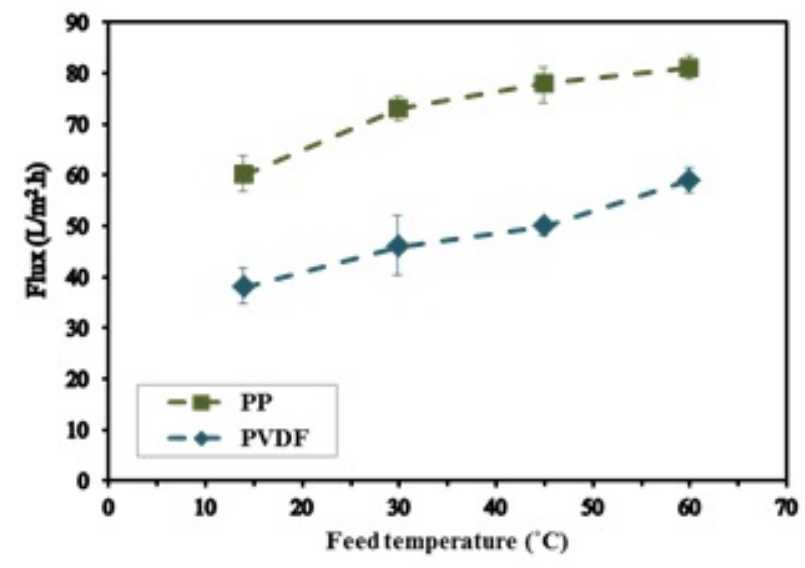

Figure 8: Effect of feed temperature on permeate flux.

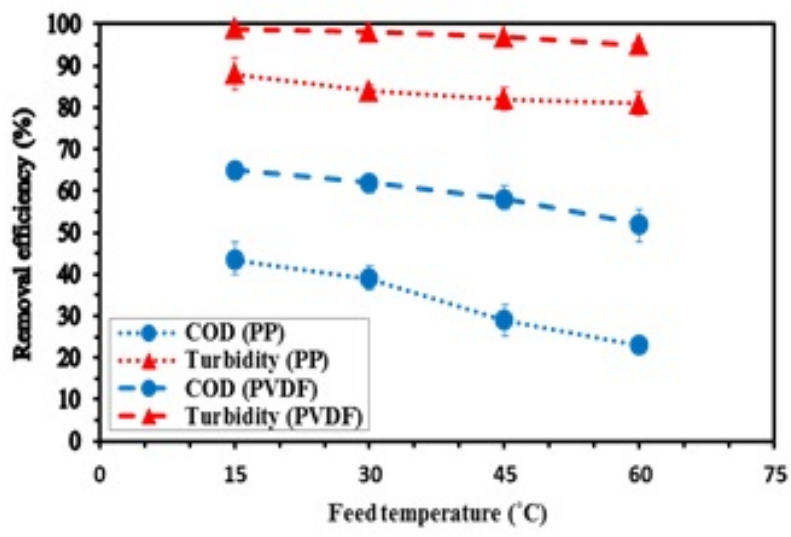

Figure 9: Effect of feed temperature on COD and turbidity removal.

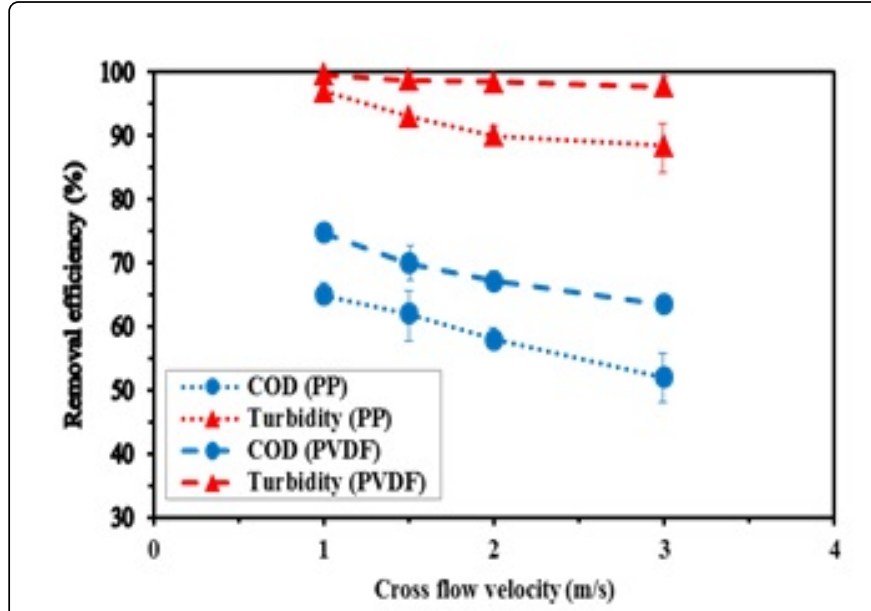

Figure 10: Effect of cross flow velocity on COD and turbidity removal.

Increasing cross flow velocity through the UF membrane leads to a decline in COD and turbidity removal efficiency Figure 11. This phenomenon might be affected by the formation of fouling layer. At low velocity, the fouling layer easily grew and natural organic matter can accumulate on this layer. The fouling layer acted as another filter layer that increased the resistance of passing organic matter through the membrane. The adsorption or precipitation of organic matter on the fouling layer leads to substantial reductions of the turbidity and the concentration of COD in the permeate which would result in higher removal efficiency $[57,58]$.

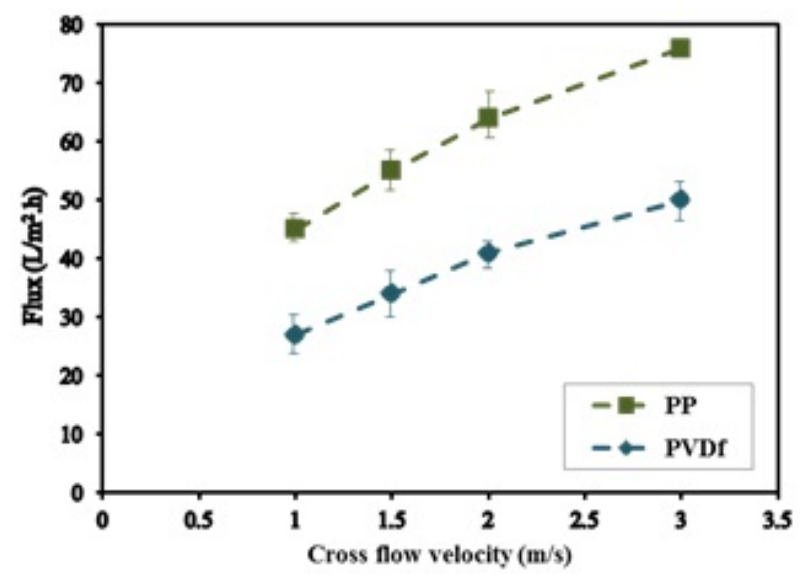

Figure 11: Effect of cross flow velocity on permeate flux.

The integrated system of CC-UF shows a better separation performance in comparison to UF only and coagulation only systems. Jin et al. [59] reported a $25 \%$ increase in DOC removal using in-line CC-UF treatment rather UF direct. Performance of UF is improved by coagulation owing to incline the concentration of particles that can pass through pores and block them, or form a high resistance barrier as a filter cake [60]. The indicated results in Figure 12 confirms that 
CC-UF system compared with UF-alone is more effective in terms of pollution removal efficiency and consequently control UF fouling.

\section{Conclusions}

In this study, the effects of coagulant concentration and initial $\mathrm{pH}$ for three types of coagulants were investigated. The results suggested that the removal efficiency of COD and turbidity using PACl as coagulant were higher than alum and lime. The results indicated that initial $\mathrm{pH}$ is a significant factor in the removal of turbidity and COD. The optimum $\mathrm{pH}$ for $\mathrm{PACl}$ was 8-10.

The results show high efficiency of PACl compare other coagulant. The reason can be absorption onto the positively charged surface of the hydroxo-complexes due to Melanoidins functional groups through electrostatic attraction. Moreover, the results of combinations of coagulants showed using two-stage coagulation by $\mathrm{PACl}$ and limein the concentrations of $500 \mathrm{mg} / \mathrm{L} \mathrm{PACl}$ and $1800 \mathrm{mg} / \mathrm{L}$ lime by COD removal of $68 \%$ and turbidity removal of $81 \%$ was the most effective membrane pretreatment method. On the one hand, using two-stage coagulation improved the quality of pretreated wastewater of the UF; on the other hand, $\mathrm{pH}$ in the alkaline range was adjusted due to alkalinity property of lime. Using the membrane filtration for treatment of this wastewater was an acceptable and suitable method. Appropriate output characteristics, easy operating conditions, the ability to combine with some other processes (biological and chemical) and eventually easier system controlling were significant advantages of this method. In addition, little dependency of output characteristics to the characteristics of feed was one of the positive points of membrane filtration treatment method. The experiments showed that increasing transmembrane pressure, temperature and cross flow velocity, increased permeate flux and decreased turbidity and COD removal efficiency of wastewater. In this study, two different UF membranes were investigated to determine the advantages and disadvantages of each one. As a result, PVDF membrane provided a permeate flow with less pollution than PP membrane with about $99 \%$ turbidity and $91 \%$ COD removal while the permeate flux in PVDF membrane was lower than PP membrane.

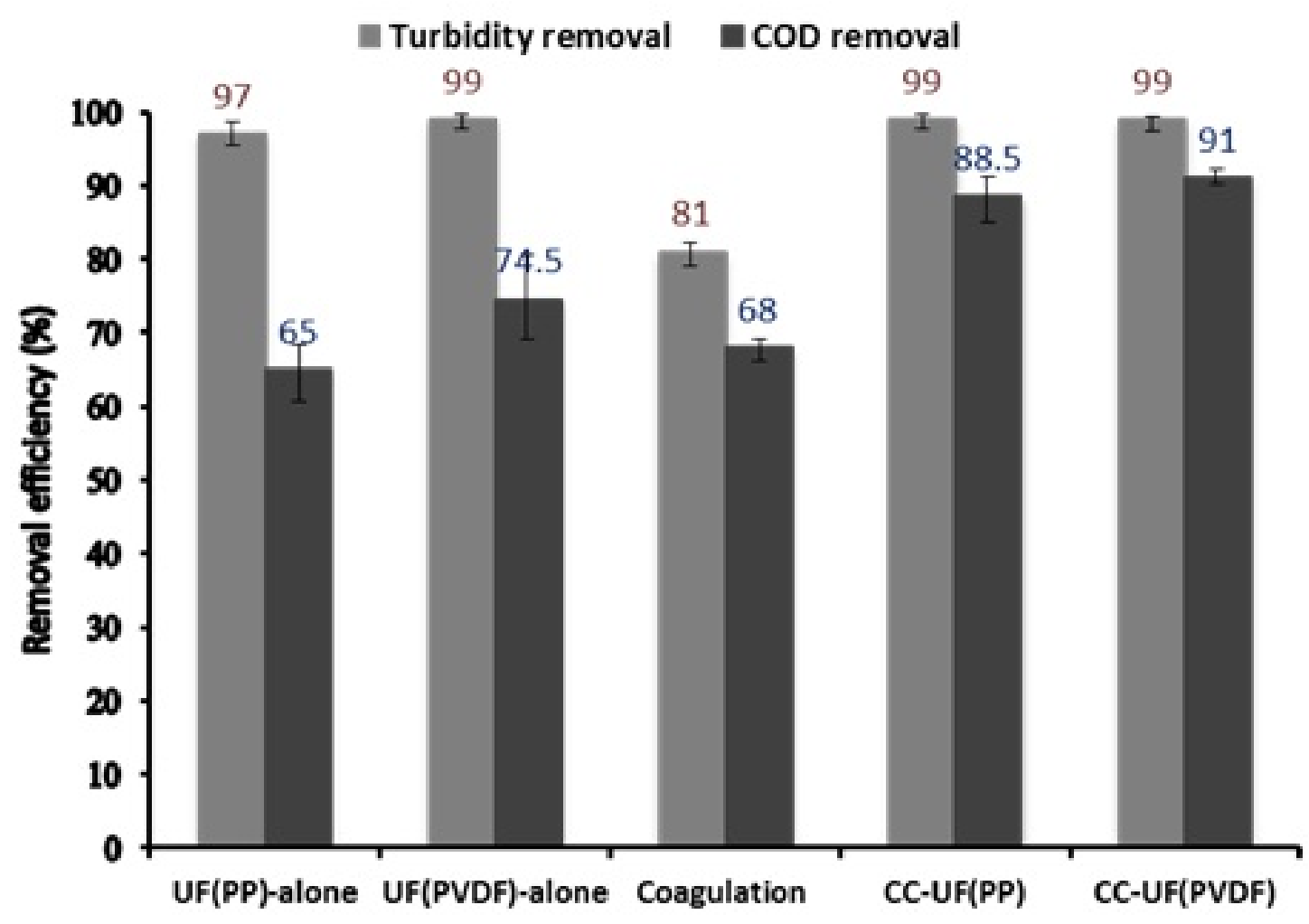

Figure 12: Comparison of combined CC-UF with UF-alone and coagulation-alone treatments in removal efficiency.

\section{References}

1. Smith DW, Mavinic DS, Zytner RG (2002) Future directions of environmental engineering in Canada. J Environ Eng Sci, 1: 9-16.

2. Maher A, Sadeghi M, Moheb A (2014) Heavy metal elimination from drinking water using nanofiltration membrane technology and process optimization using response surface methodology. Desalination, 352:166-173.
3. Chang I, Lee C, Ahn K (1999) Membrane filtration characteristics in membrane-coupled activated sludge system: The effect of floc structure on membrane fouling. Separ Sci Technol 34: 1743-1758.

4. Abdessemed D, Nezzal G, Aim RB (1999) Treatment of wastewater by ultrafiltration. Desalination 126: 1-5.

5. Mokhtar NM, Lau WJ, Ismail A, Youravong W, Khongnakorn W, et al. (2015) Performance evaluation of novel PVDF-Cloisite 15A hollow fiber composite membranes for treatment of effluents containing dyes and salts using membrane distillation. RSC Adv 5: 38011-38020. 
6. Kang GD, Cao YM (2014) Application and modification of poly (vinylidene fluoride)(PVDF) membranes-A review. J Membrane Sci 463 145-165.

7. Jing Y, Chaplin BP (2016) Electrochemical impedance spectroscopy study of membrane fouling characterization at a conductive sub-stoichiometric $\mathrm{TiO} 2$ reactive electrochemical membrane: Transmission line model development. J Membrane Sci 511: 238-249.

8. Zielińska M, Bułkowska $\mathrm{K}$, Cydzik-Kwiatkowska A, Bernat $\mathrm{K}$, Wojnowska-Baryłam I (2016) Removal of bisphenol A (BPA) from biologically treated wastewater by microfiltration and nanofiltration. Int J Environ Sci Technol 13: 2239-2248.

9. Jung CW, Son HJ, Kang LS (2006) Effects of membrane material and pretreatment coagulation on membrane fouling: fouling mechanism and NOM removal. Desalination, 197: 154-164.

10. Bz Dong, C Yan, Ny Gao, Jc Fan (2007) Effect of coagulation pretreatment on the fouling of ultrafiltration membrane. J ENVIRON SCI, 19:278-283.

11. Šostar-Turk S, Petrinić I, Simonič M, (2005) Laundry wastewater treatment using coagulation and membrane filtration. Resour Conserv Recy 44: 185-196.

12. Kim SH, Moon SY, Yoon CH, Yim SK, Cho JW (2005) Role of coagulation in membrane filtration of wastewater for reuse. Desalination, 173:301-307.

13. Mutlu S, Yetis U, Gurkan T, Yilmaz L (2002) Decolorization of wastewater of a baker's yeast plant by membrane processes. Water Res 36: 609-616.

14. Lee BB, Choo KH, Chang D, Choi SJ (2009) Optimizing the coagulant dose to control membrane fouling in combined coagulation/ ultrafiltration systems for textile wastewater reclamation. Chem Eng J 155: 101-107.

15. Wang W, Zhao S, Yue Q, Gao B, Song W, et al. (2016) Purification, characterization and application of dual coagulants containing chitosan and different $\mathrm{Al}$ species in coagulation and ultrafiltration process. J Environ Sci 51: 214-221.

16. MA Sari, S Chellam (2013) Surface water nanofiltration incorporating (electro) coagulation-microfiltration pretreatment: Fouling control and membrane characterization. J MEMBRANE SCI, 437:249-256.

17. Aouni A, Fersi C, Ali MBS, Dhahbi M (2009) Treatment of textile wastewater by a hybrid electrocoagulation/nanofiltration process. J Hazard Mater 168: 868-874.

18. Cai Z, Kim J, Benjamin MM (2007) NOM removal by adsorption and membrane filtration using heated aluminum oxide particles. Environ $\mathrm{Sci}$ Technol 42: 619-623.

19. Schlichter B, Mavrov V, Chmiel H (2003) Study of a hybrid process combining ozonation and membrane filtration-filtration of model solutions. Desalination 156: 257-265.

20. Park Pk, Lee CH, Choi SJ, Choo KH, Kim SH, et al. (2002) Effect of the removal of DOMs on the performance of a coagulation-UF membrane system for drinking water production. Desalination 145: 237-245.

21. Matilainen A, Vepsäläinen M, Sillanpää M (2010) Natural organic matter removal by coagulation during drinking water treatment: a review. Adv Colloid Interfac 159: 189-197.

22. Kim SC (2016) Application of response surface method as an experimental design to optimize coagulation-flocculation process for pre-treating paper wastewater. J Ind Eng Chem 38: 93-102.

23. Ebrahimi A, Taheri E, Pashaee A, Mahdavi M (2015) The effectiveness of polyaluminum ferric chloride (PAFCl) for turbidity and color removal from Isfahan raw water. Desalin Water Treat 55: 1966-1972

24. Changqing Y, Dongsheng W, Xiaohong W, Jiuhui Q, Gregory J (2009) Modified ferron assay for speciation characterization of hydrolyzed $\mathrm{Al}$ (III): a precise $\mathrm{k}$ value based judgement. Water Sci Technol 59: 823-832.

25. Reitzel K, Jensen HS, Egemose S (2013) pH dependent dissolution of sediment aluminum in six Danish lakes treated with aluminum. Water research 47: 1409-1420.

26. Gengec E, Kobya M, Demirbas E, Akyol A, Oktor K (2012) Optimization of baker's yeast wastewater using response surface methodology by electrocoagulation. Desalination 286: 200-209.
27. Kobya M, Delipinar S (2008) Treatment of the baker's yeast wastewater by electrocoagulation. J Hazard Mater 154: 1133-1140.

28. Nahid P, Vossoughi M, Alemzadeh I (2001) Treatment of baker's yeast wastewater with a Biopack system. Process Biochem 37:447-451.

29. Pirsaheb M, Rostamifar M, Mansouri A, Zinatizadeh A, Sharafi K ( Performance of an anaerobic baffled reactor (ABR) treating high strength baker's yeast manufacturing wastewater. J Taiwan Inst Chem E, 47: $137-148$.

30. Liang Z, Wang Y, Zhou Y, Liu H (2009) Coagulation removal of melanoidins from biologically treated molasses wastewater using ferric chloride. Chem Eng J 152: 88-94.

31. Liang Z, Wang Y, Zhou Y, Liu H, Wu Z (2009) Variables affecting melanoidins removal from molasses wastewater by coagulation/ flocculation. SEP PURIF TECHNOL 68: 382-389.

32. Zhou Y, Liang Z, Wang Y (2008) Decolorization and COD removal of secondary yeast wastewater effluents by coagulation using aluminum sulfate. Desalination 225: 301-311.

33. Gengec E (2015) Color removal from anaerobic/aerobic treatment effluent of bakery yeast wastewater by polyaniline/beidellite composite materials. J Environ Chem Eng 3: 2484-2491.

34. Balcıŏlu G, Gönder ZB (2014) Recovery of baker's yeast wastewater with membrane processes for agricultural irrigation purpose: Fouling characterization. Chem Eng J 255: 630-640.

35. Tsioptsias C, Petridis D, Athanasakis N, Lemonidis I, Deligiannis A, et al. (2015) Post-treatment of molasses wastewater by electrocoagulation and process optimization through response surface analysis. J Environ Manage 164: 104-113.

36. Kalyuzhnyi S, Gladchenko M, Starostina E, Shcherbakov S, Versprille A (2005) Combined biological and physico-chemical treatment of baker's yeast wastewater. Water Sci Technol 52: 175-181.

37. Liu F, Hashim NA, Liu Y, Abed MM, Li K (2011) Progress in the production and modification of PVDF membranes. J Membrane Sci 375: $1-27$.

38. Nosratpour MJ, Sadeghi M, Karimi K, Ghesmati S (2015) Efficient treatment of baker's yeast wastewater using aerobic membrane bioreactor. 3: $105-111$.

39. Wu T, Zhou B, Zhu T, Shi J, Xu Z, et al. (2015) Facile and low-cost approach towards a PVDF ultrafiltration membrane with enhanced hydrophilicity and antifouling performance via graphene oxide/waterbath coagulation. RSC Adv 5: 7880-7889.

40. Liakos TI, Lazaridis NK (2014) Melanoidins removal from simulated and real wastewaters by coagulation and electro-flotation. Chem Eng J 242: 269-277.

41. Soh YC, Roddick F, Leeuwen JV (2008) The impact of alum coagulation on the character, biodegradability and disinfection by-product formation potential of reservoir natural organic matter (NOM) fractions. Water Sci Technol 58: 1173-1179.

42. Barzegari Z, Bina B, Pourzamani H, Ebrahimi A (2016) The combined treatment of bisphenol A (BPA) by coagulation/flocculation (C/F) process and UV irradiation in aqueous solutions. Desalin Water Treat 57: 8802-8808.

43. Klimiuk E, Filipkowska U, Korzeniowska A (1999) Effects of pH and Coagulant Dosage on Effectiveness of Coagulation of Reactive Dyes from Model Wastewater by Polyaluminium Chloride (PAC). Polish Journal of Environmental Studies 8: 73-79.

44. López-Maldonado E, Oropeza-Guzman M, Jurado-Baizaval J, OchoaTerán A (2014) Coagulation-flocculation mechanisms in wastewater treatment plants through zeta potential measurements. J Hazard Mater 279: 1-10.

45. Wilczak A, Howe EW, Aieta EM, Lee RG (1992) How peroxidation affects particle removal during clarification and filtration. J Am Water Works Assoc 84: 85-94.

46. He J, Liu F, Ouyang L, Kang X (2011) Optimum Operating Conditions Confirmation and Effectiveness Analysis Based on Research of the 
Citation: $\quad$ Alavijeh HN, Sadeghi M, Rajaeieh M, Moheb A, Sadani M, et al. (2017) Integrated Ultrafiltration Membranes and Chemical

Coagulation and Precipitation Integrated Process. Procedia Environ Sci 10: 541-548

47. Wei N, Zhang Z, Liu D, Wu Y, Wang Q, et al. (2015) Coagulation behavior of polyaluminum chloride: Effects of $\mathrm{pH}$ and coagulant dosage. Chinese J Chem Eng 23: 1041-1046.

48. Liu T, Chen Zl, Yu WZ, Shen JM, Gregory J (2011) Effect of two-stage coagulant addition on coagulation-ultrafiltration process for treatment of humic-rich water. Water Res 45: 4260-4268.

49. Sun D, Duan X, Li W, Zhou D (1998) Demulsification of water-in-oil emulsion by using porous glass membrane. J Membrane Sci 146: 65-72.

50. Ahmad A, Ismail S, Bhatia S (2005) Membrane treatment for palm oil mill effluent: effect of transmembrane pressure and cross flow velocity. Desalination 179: 245-255.

51. Mohammadi T, Moghadam MK, Madaeni S (2003) Hydrodynamic factors affecting flux and fouling during reverse osmosis of seawater. Desalination 151: 239-245.

52. Sharma RR, Chellam S (2005) Temperature effects on the morphology of porous thin film composite nanofiltration membranes. Environ Sci Technol 39: 5022-5030.

53. Hlavacek M (1995) Break-up of oil-in-water emulsions induced by permeation through a microfiltration membrane.J Membrane Sci 102: $1-7$.
54. Goosen MF, Sablani SS, Al-Maskari SS, Al-Belushi RH, Wilf M (2002) Effect of feed temperature on permeate flux and mass transfer coefficient in spiral-wound reverse osmosis systems. Desalination 144: 367-372.

55. Jin X, Jawor A, Kim S, Hoek EM (2009) Effects of feed water temperature on separation performance and organic fouling of brackish water RO membranes. Desalination 239: 346-359.

56. Sadeghian M, Sadeghi M, Hesampour M, Moheb A (2014) Application of response surface methodology (RSM) to optimize operating conditions during ultrafiltration of oil-in-water emulsion. Desalin Water Treat 55: $1-9$.

57. Ahmad A, Ismail S, Bhatia S (2005) Ultrafiltration behavior in the treatment of agro-industry effluent: pilot scale studies. Chem Eng Sci 60: 5385-5394.

58. Mikulášek P, Doleček P, Pospišil P (2004) Crossflow microfiltration of mineral dispersions using ceramic membranes.Desalination 163: 333-343.

59. Jin W, Wang XC (2006) Ultrafiltration with in-line coagulation for the removal of natural humic acid and membrane fouling mechanism. J Environ Sci 18: 880-884.

60. Shang X, Kim HC, Huang JH, Dempsey BA (2015) Coagulation strategies to decrease fouling and increase critical flux and contaminant removal in microfiltration of laundry wastewater. Separ Purif Method 147: 44-50. 